\title{
Información nutrimental del etiquetado de productos de mar en conserva
}

\author{
Nutritional Information on the Labelling of Canned Products Seafood \\ Covarrubias-Cruz Gerardo ${ }^{a}$, Espinoza-Gayosso Nohemí ${ }^{b}$, García-Luna Amalfi M ${ }^{c}$, Mejia- \\ Abreo Beatriz A ${ }^{d}$, Ramírez-Moreno $E^{e}$, Calderón-Ramos Zuli $G^{f}$
}

\begin{abstract}
:
The labeling of the processed products allows us to know the food, its origin, its way of conservation, the ingredients that make up the nutrients that contribute to our diet. Canned seafood products do not carry chemical preservatives, since the natural sterilization procedure is sufficient to keep the product intact. The objective of this work was to review the canned seafood products. The products of the sea are a good source of protein with values between 7 and $29 \mathrm{~g} / 100 \mathrm{~g}$ of product, and a high biological value that covers the amount of protein by a suggestion that we should consume daily. The lipid content of these products is usually low although only one product has $29 \mathrm{~g}$ of lipids. These fats are of great nutritional importance due to the contribution of omega- 3 . The sodium concentration ranged from 170 mg to $800 \mathrm{mg}$. Only the presentation of some brands complies with the content of the protein, lipids, and sodium that mark the guidelines established by the established standards of labeling.
\end{abstract}

\section{Key Words:}

Canned, sea products, labeling

\section{Resumen}

El etiquetado de los productos procesados nos permite conocer el alimento, su origen, su modo de conservación, los ingredientes que lo componen o los nutrientes que aportan a nuestra dieta. Los productos de mar enlatados no llevan conservadores químicos, ya que el procedimiento natural de la esterilización basta para mantener intacto el producto. El presente trabajo tuvo como objetivo hacer una revisión de distintos productos de mar enlatados. Los productos del mar son considerados una buena fuente de proteína con valores entre 7 y 29 g/100 g de producto, y de alto valor biológico que cubre la cantidad de proteína por porción sugerida que debemos consumir al día. El contenido lipídico de estos productos suele ser bajo aunque solo un producto presento 29 g de lípidos. Estas grasas tienen gran importancia nutrimental por su aporte de omega-3. La concentración de sodio varió de $170 \mathrm{mg}$ hasta $800 \mathrm{mg}$. Solo la presentación de algunas marcas cumplía con el contenido de proteína, lípidos, y sodio que marcaban los lineamientos establecidos por las normas establecidas de etiquetado.

Palabras Clave:

Enlatados, productos de mar, etiquetado

\footnotetext{
* Autor de correspondencia, Universidad Autónoma del Estado de Hidalgo, Instituto de Ciencias de la Salud, Área Académica de Nutrición, ORCID: https://orcid.org/0000-0001-1234-1234, Email: gcovarrubiascruz@uaeh.edu.mx

b Universidad Autónoma del Estado de Hidalgo, Instituto de Ciencias de la Salud, Área Académica de Nutrición, Email: nohemi170797@hotmail.com

c Universidad Autónoma del Estado de Hidalgo, Instituto de Ciencias de la Salud, Área Académica de Nutrición, Email: monse_wamba@live.com.mx

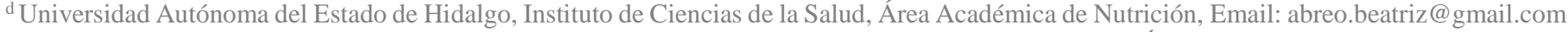
e Autor principal, Universidad Autónoma del Estado de Hidalgo, Instituto de Ciencias de la Salud, Área Académica de Nutrición, Email: esther_ramirez@uaeh.edu.mx

f Universidad Autónoma del Estado de Hidalgo, Instituto de Ciencias de la Salud, Área Académica de Nutrición, Email: calderonramos@yahoo.com.mx
} 


\section{Introducción}

La industria de productos marinos requiere tecnologías de etiquetado que ofrezcan eficiencia, velocidad y el cumplimiento de ciertas normas y requisitos de inocuidad y respeto del medio ambiente que exigen los mercados. Para que los productos salgan a la venta, se necesita que cubran todos los requisitos que les exige la Norma Oficial Mexicana NOM-051-SCFI/SSA1-2010 ${ }^{1}$.

La NMX-F-220-1982 establece la regulación de productos en conserva como el atún y pescados similares en aceite enlatados ${ }^{2}$.

El etiquetado nos permite conocer el alimento, su origen, su modo de conservación, los ingredientes que lo componen o los nutrientes que aportan a nuestra dieta. La información nutrimental de un alimento se refiere a su valor energético y sus nutrientes: grasas, grasas saturadas, hidratos de carbono, azúcares, proteínas y sodio, por eso es importante que haya una regulación ${ }^{3}$.

Los productos de mar enlatados no llevan conservadores químicos, ya que el procedimiento natural de la esterilización basta para mantener intacto el producto. Es un modo de conservación de los alimentos, segura, sana y con todas las propiedades nutritivas del alimento. Este proceso de conservación no afecta la naturaleza de las proteínas, grasas e hidratos de carbono de los alimentos ${ }^{4}$.

Los productos de mar presentan componentes naturales de gran importancia nutricional como son: el aceite de oliva o vegetal, por la cantidad de antioxidantes naturales que aporta y de ácido oleico y linolénico. Estos ácidos grasos esenciales, el cuerpo no los sintetiza y debe obtenerlos de los alimentos $^{5}$. La importancia de estos acidos grasos poliinsaturados radica en el mantenimiento de membranas celulares y ayuda reducir las concentraciones de triglicéridos en sangre ${ }^{6}$.

Estos líquidos son idóneos para mantener la melosidad de la carne de pescado. El pescado en conserva además aporta proteínas de alto valor biológico, minerales (potasio, fósforo, magnesio, hierro, calcio, sodio) y vitaminas liposolubles e hidrosolubles. Asimismo las sardinas presentan ácidos grasos poliinsaturados omega 3 y proteínas de excelente calidad, contribuyendo con un 20 y $50 \%$ de las IDR de calcio y fósforo respectivamente, la importancia de estos minerales es que participan en el mantenimiento de dientes y huesos brindándoles rigide ${ }^{7}$.

La principal limitación a nivel nutricional que presentan las conservas es el contenido de sodio, que se emplea como aditivo o conservante. De acuerdo con Cenarro \& Ruíz (2016) 100 g de pescado en conserva aporta $300 \mathrm{mg}$ de sodio ${ }^{3}$.

\section{Objetivos}

Revisar la información nutrimental del etiquetado de los productos de mar: atún, sardina, ostiones y mejillones para determinar si cumplen los lineamientos que dicta la Norma Oficial Mexicana NOM-051-SCFI/SSA1-2010.

Comparar entre los productos cuál de las marcas presenta mejor calidad de acuerdo al contenido nutrimental y aditivos establecido por la Norma Oficial Mexicana NOM-051-SCFI/SSA1-2010.

\section{Metodología}

1. Se seleccionaron los productos: atún, sardina, mejillones y ostiones enlatados que se expenden en supermercados de Pachuca de Soto.

2. La información de los productos marinos en conserva se presentó en tablas comparativas incluyendo la información nutrimental (kcals, proteína, lípidos, carbohidratos, sodio) y precio de cada uno de ellos. 


\section{Resultados y discusión}

Tabla 1. Comparación nutrimental y precios de distintos tipos de atún enlatado (g/100 g).

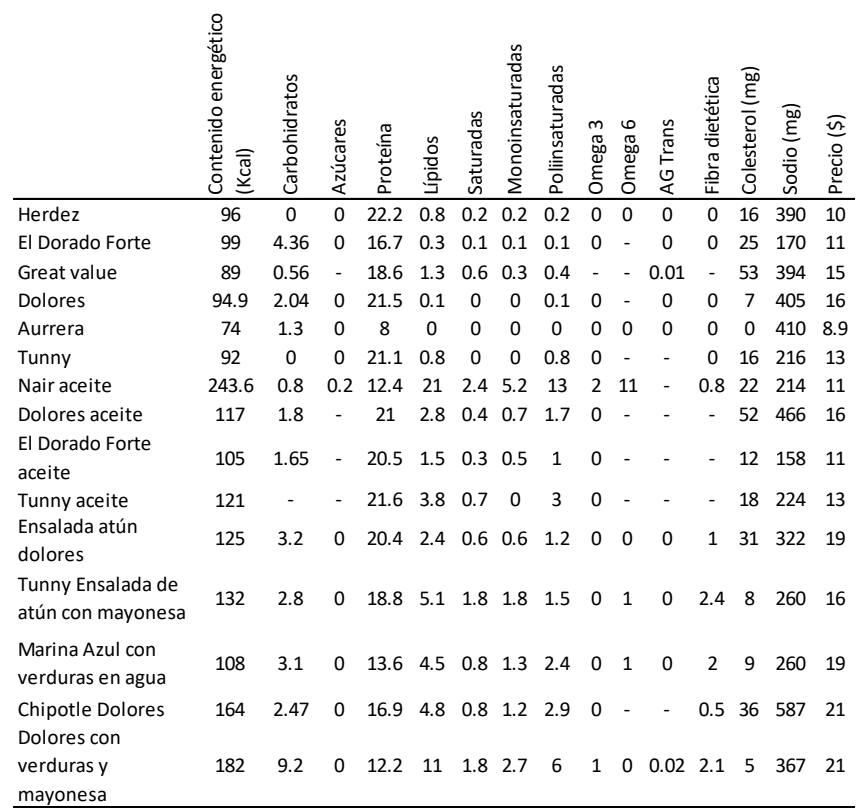

En la tabla 1 se organizó la información considerando si el atún tenía una presentación en agua, aceite $u$ otros ingredientes como vegetales y aderezos. De manera general, los atunes con presentación de aceite o con otros ingredientes aportan una mayor cantidad de energía. El contenido calórico de atún en aceite Nair proporciona una mayor cantidad de energía (243.6 kcal). En el caso de las sardinas ninguna de las muestras sobrepasa las $200 \mathrm{kcal}$, sin embargo, los mejillones en escabeche PONTO refiere el contenido calórico más alto encontrado con respecto a los demás alimentos analizados, esto se debe al alto contenido lipídico (29\%) (Tabla 2).

Los ácidos grasos que se encontraron en estos productos fueron saturados, mono insaturados y en mayor concentración poliinsaturados. Dentro de estos últimos es importante la presencia de omega-3. Aunque no todos los productos indican la cantidad de omega-3, sin embargo estos productos se consideran ricos en este componente. Otro tipo de grasas que pudieran presentar estos productos fueron las grasas trans y solo las marcas de atún Great Value y Dolores con verduras y mayonesa lo refieren en su etiquetado en muy baja concentración (0.02 $\mathrm{g} / 100 \mathrm{~g}$ ).

De acuerdo a la Procuraduría Federal del Consumidor en el $2012{ }^{8}$ establece que los alimentos de mar enlatados son considerados proteicos cuando su aporte se encuentre entre 10 y 24 gramos por cada 100 gramos de
Tabla 2. Comparación nutrimental y precio de distintos tipos de sardina, mejillones y ostiones $(\mathrm{g} / 100 \mathrm{~g})$.

\begin{tabular}{|c|c|c|c|c|c|c|c|c|c|c|c|c|c|c|c|}
\hline & 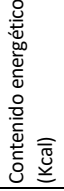 & 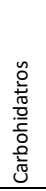 & 岕 & 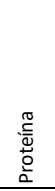 & $\begin{array}{l}\text { 음 } \\
\text { :을 }\end{array}$ & 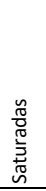 & 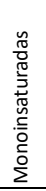 & 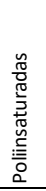 & 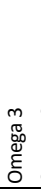 & 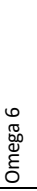 & 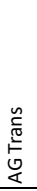 & 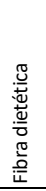 & 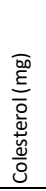 & 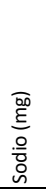 & $\begin{array}{l}\sqrt{n} \\
\frac{0}{\bar{u}} \\
\frac{0}{2}\end{array}$ \\
\hline Aurrera Sardina & 116 & 3 & 0 & 10 & 7 & 6 & - & - & - & - & - & 3 & - & 491 & 23 \\
\hline Yavaros & 112 & 1.4 & 0 & 15.4 & 5.4 & 2.3 & - & - & - & - & - & 1.2 & - & 384 & 26 \\
\hline $\begin{array}{l}\text { PONTO (Sardina en } \\
\text { aceite de oliva) }\end{array}$ & 152 & 2 & 0 & 7 & 20 & 1.2 & 4.6 & 1 & 1 & 0 & 0 & 0 & 121 & 351 & 25 \\
\hline $\begin{array}{l}\text { PONTO (Sardina en } \\
\text { salsa de tomate) }\end{array}$ & 120 & 1.2 & 0 & 16 & 5.6 & 1.6 & 0.9 & 2.8 & 2 & 0 & 0 & 0 & 68 & 352 & 19 \\
\hline $\begin{array}{l}\text { PONTO (Sardina en } \\
\text { aceite de soya con } \\
\text { picante) }\end{array}$ & 200 & 22 & 0 & 16 & 5.4 & 1 & 1 & 3.2 & 2 & 0 & 0 & 0 & 94 & 392 & 19 \\
\hline $\begin{array}{l}\text { PONTO (Sardina en } \\
\text { salsa chipotle) }\end{array}$ & 120 & 1.2 & 0 & 16 & 5.6 & 1.6 & 0.9 & 2.8 & 2 & 0 & 0 & 0 & 68 & 352 & 19 \\
\hline $\begin{array}{l}\text { PONTO (Sardina en } \\
\text { aceite de soya) }\end{array}$ & 200 & 22 & 0 & 16 & 5.4 & 1 & 1 & 3.2 & 2 & 0 & 0 & 0 & 94 & 332 & 19 \\
\hline Guaymex & 120 & 1.2 & 0 & 16 & 5.6 & 1.6 & 0.9 & 2.8 & 2 & - & 0 & 0 & 68 & 352 & 25 \\
\hline $\begin{array}{l}\text { Mejillones: Cabo de } \\
\text { peñas en escabeche }\end{array}$ & 159.9 & 5 & 0 & 18.1 & 7.5 & 1.1 & - & - & - & - & - & 0 & - & 800 & 29 \\
\hline $\begin{array}{l}\text { PONTO (Mejillones } \\
\text { en escabeche) }\end{array}$ & 312 & 0.5 & 0 & 12 & 29 & 2.8 & - & - & - & - & - & 0.5 & - & 620 & 30 \\
\hline $\begin{array}{l}\text { PONTO (Ostiones } \\
\text { en escabeche) }\end{array}$ & 190 & 3.6 & 0 & 19.6 & 11 & 2.6 & - & - & - & - & - & 0 & - & 286 & 39 \\
\hline
\end{tabular}

producto comestible. Todos los productos evaluados se encontraron dentro de este rango establecido, excepto el atún en agua marca Aurrera (tabla 1) y la sardina en aceite de oliva PONTO que tuvieron un contenido bajo $(\approx 8 \mathrm{~g} / 100$ g) (tabla 2).

La mayoría de los productos analizados presentó bajas cantidades de hidratos de carbono, esto se debe a que estos animales agotan la glucosa como fuente de energía en el momento de la captura. Estos productos no deben contener fibra dietética puesto que son de alimentos de origen animal, no obstante, la Sardina marca Aurrera presentó la mayor cantidad de fibra dietética $(3 \mathrm{~g})$ debido a que en su contenido se encuentra soya texturizada. Los mariscos contienen un aporte calórico bajo (80 a 100 $\mathrm{Kcal} / 100 \mathrm{~g}$ ), sin embargo, generalmente durante la elaboración y enlatado de los productos se utilizan extractos vegetales, afectando 
significativamente el aporte de calorías en estos productos $^{5}$.

Estos productos son considerados altos en sodio, debido a que presentaron una cantidad de158 a $800 \mathrm{mg} / 100 \mathrm{~g}$. De acuerdo con la NOM 086-SSA1-1994 los productos que presentan un valor mayor de $600 \mathrm{mg} /$ porción son considerados alimentos altos en sodio ${ }^{9}$. El mayor contenido de sodio lo presentaron los mejillones en escabeche de la marca Cabo de Peñas. El tipo de sal que debe de utilizarse en la elaboración de estos productos debe ser yodatada y fluorurada. Debido al alto contenido de sal de estos productos, se recomienda drenar el producto previo a su consumo ${ }^{10}$.

El precio de estos productos va de 8 a 39 pesos, lo cual dependen de varios factores, como la presencia de vegetales y productos derivados de la soya que abaratan el producto. De acuerdo a la NOM-084-SCFI-1994 se permiten cantidades de hasta $2 \%$ en peso de otros constituyentes al atún, sin embargo, el etiquetado solo advierte sobre la presencia de soya y no la cantidad que incluye ${ }^{8,11,12}$. Recientemente un informe establecido por la PROFECO dio a conocer que algunas presentaciones de atún enlatado contienen soya en un porcentaje que va del $1.0 \%$ al $62 \%$ de la masa drenada. Por lo que establece que en algunos casos el consumidor no está adquiriendo atún, sino soya con atún, lo cual se considera una práctica fraudulenta. Entre los productos de atún analizados en ese estudio, se determinó que las marcas que contienen soya son, Aurrera en agua (24-36\%), Dolores en aceite (1$2 \%$ ), Dolores en agua (1-3\%), Great Value en agua (6$16 \%$ ), El Dorado en agua (13-22\%) y El Dorado en aceite (21-44\%). Cabe mencionar que uno de los atunes que no presentó soya en su composición es el de la marca Herdez en todas sus presentaciones ${ }^{13}$.

Los productos presentaron aditivos como el diacetato de sodio que se utiliza como conservador (atún Dolores con chipotle), goma xantana (atún Tunny con mayonesa, sardinas marca Aurrera y Yavaros) como espesante para dar consistencia al producto ${ }^{12}$.

También se utilizan especias y condimentos como el aceite vegetal de soya que se presentó en todos los atunes en aceite y que por norma (NOM-084-SCFI-1994) no debe exceder del $5 \%$ del volumen del envase ${ }^{12}$.

\section{Conclusión}

El pescado en conserva es una buena fuente de proteína, de alto valor biológico que cubre la cantidad por porción sugerida que debemos consumir al día además de lípidos de alto valor biológico, como el omega-3, vitaminas y minerales. Sin embargo, su consumo debe ser prudente debido a que son considerados productos con un alto contenido de sodio, es importante leer cuidadosamente las etiquetas antes de comprar los productos para conocer los ingredientes $u$ aditivos que contienen.

\section{Referencias}

1. Norma Oficial Mexicana NOM-051-SCFI/SSA1-2010. Especificaciones generales de etiquetado para alimentos y bebidas no alcohólicas preenvasados-Información comercial y sanitaria.

2. NMX-F-220-1982. Alimentos para uso humano. pesca. atún y pescados similares en aceite enlatados. food for human use. fishery canned tunny and similer fishes in oil. normas mexicanas. dirección general de normas.

3. Cenarro, T., Ruiz, E. (2016). La importancia del etiquetado. Lúa Ediciones: Madrid. Vol: 3(0). Pp. 357-67.

4. Dávalos, S., Zamora, D. (2005). Alimentos marinos: tipificación y proceso de almacenamiento.

5. Secretaria de agricultura, ganadería, desarrollo rural, pesca y alimentación. (2004). PC-017-2004 Pliego de condiciones para el uso de la marca oficial México calidad suprema en atún

6. National Inastitutes of Health. (2018). Ácidos grasos Omega 3.

7. Food and Agriculture Organization. (2015). Minerales.

8. PROFECO. (2012). Atún: todo cabe en una latita.

9. Norma Oficial Mexicana NOM-086-ssa1-1994, Bienes y servicios. Alimentos y bebidas no alcohólicas con modificaciones en su composición. Especificaciones nutrimentales.

10. Norma Oficial Mexicana NOM-040-SSA1-1993. Productos y servicios. Sal yodada y sal yodada fluorurada. Especificaciones sanitarias.

11. Greenfield, H., Southgate, D. (2003). Datos de composición de los alimentos. Australia: Organización de las Naciones Unidas para la Agricultura y la Alimentación.

12. Norma Oficial Mexicana NOM-084-SCFI-1994.Informacion comercial y sanitaria para productos de atún y bonita preenvasados.

13. PROFECO. (2019). Atún envasado. Revista del consumidor. 